\title{
EXPERIMENTING PARTICIPATIVE E-LEARNING IN NON- FORMAL ADULT EDUCATION: THE ESCALADE PROJECT
}

\author{
Luis Ochoa Siguencia \\ Kukuczka Academy of Physical Education in Katowice, Poland \\ Gilberto Marzano \\ Rezekne Academy of Technologies, Latvia \\ Renata Ochoa-Daderska \\ Research and Innovation in Education Institute, Poland
}

\begin{abstract}
This paper presents the research approach designed for EScAlADE, an EU funded project that sees the participation of five European countries and focuses on adult participative e-learning. EScAlADE aims at investigating about the educational needs of adults (range: 50-65 years) involved in e-learning programs. This paper reports on the projects methodology and on the necessity of educational strategies able to provide adult trainees with the skills required by the labor market.
\end{abstract}

Keywords: Participative e-learning, non-formal education, Long-life learning, research project management.

\section{Introduction}

In 2012, the unemployment rate for low-qualified adults was $16.8 \%$, compared to $8.6 \%$ for the medium-skilled and $5.6 \%$ for the high-skilled group (Eurostat, 2013). Lifelong learning is still considered one of the main ways to stay in the labor market or to find a new job but many adults - especially workers in the range-of 50-65 years, who lost or are about to lose their work are low skilled; they come from a low profile job and they are unused to attend training courses (McKenzie \& Wurzburg, 1997; European Commission, 2009; Stephenson \& Yorke, 2013; Fejes, 2014).

Generally, people are not attracted to formal or non-formal educational programs, although in some cases they are ,forced" by national policies to attend professional refresher courses, workshops and short study periods. Often participants attending forced trainings leave them before completion, since they get bored and deem them of any usefulness.

Accordingly, the re-employability of these people appears difficult, particularly in a quickly changing society. In this perspective, the definition of new learning approaches which are able to not discourage learners and take into account the possibility offered by the new technology becomes strategic. 
There exists a wide literature on participative learning, but it tackles issues tied to the mainstream face-to-face approaches (Gorodetsky \& Barak, 2008; Connolly, 2008; Percy, 2015; Sharp, 2015).

What about the possibility of transferring a participatory approach in an eLearning environment? May this approach provide the means to limit the courses' dropout by adult learners?

\section{The EScAIADE project}

EScAlADE is an Erasmus + Strategic Partnerships KA2 project funded by European Union which involves five partner from five European countries (Italy, Latvia, Poland, Greece and Spain). It started at the end of 2015 and aims at investigating about the benefits of a participative learning approach in nonformal adult e-learning programs.

The Consortium is formed by 1 University, responsible for methodology and research, and 4 NGOs expert in non-formal educational which will experiment a participative e-learning training course. According to the declared, each partner will contribute to implement the EScALADE project with different/ complementary skills and expertise.

Objectives which have been identified in the project proposal are:

- $\quad$ to find the most appropriate and efficient methodology for the target people of the project;

- the improvement of adult education methods, overcoming the digital divide occurring in an IT-based participatory approach;

- the enhancement of adult learning effectiveness by removing the impact of negative factors into adult learning groups;

- $\quad$ to attract adult people to training systems in order to reduce the level of low qualification;

- to improve a type of training more appropriate to respond to the current labour market challenges (expulsion from the labour market, new jobs, new skills to be re- employed);

- $\quad$ to experiment tools for supporting and facilitating adult learning when an active/ participatory strategy is adopted.

The main activities that will be undertaken are:

- Research about the most effective training methodology for low qualified adult/elderly people expelled from the labour market or people who are about to lose their jobs.

- Special focus on participatory learning and Web learning communities. 
- A participative e-learning experiment in order to test the theoretical foundations of participative learning in an ICT-based environment.

- Definition of a multimedia guide and course contents:

- Proposals, recommendations, educational tools to carry out efficient courses directed to the target group of the project; contents should be organized by means of an interactive software programme.

- Trainers' training session, designed to evaluate the effectiveness of the active/participatory learning methodologies.

- Delivery of the experimental course.

- Refinement of the multimedia guide and training program according the project results

From EScAlADE project, it is expected that:

- institutions involved in adult education will benefit of the research and experiment outcomes and will exploit them in their current educational activity.

- tools will be identified aimed to help both trainers in performing their job and adult/elderly in attending courses.

- a significant impact will that place at a wide range stakeholders (temporary agencies, adult education institutions, national and international institutes for professional training, employment services).

- methodologies used can stimulate the re-employment policies, e.g. facilitating the involvement the adult/elderly people in the process of re-thinking themselves in a new labor market contest.

\section{The methodology}

The research design is vital in an experimental project while the methodology is essential for performing a research. Our approach grounds on a desk research and a survey based on a questionnaire and semi-structured interviews to a small sample of key subjects.

The output of our research will be the identification of the most efficient learning methodology for low qualified adult/elderly people expelled from the labour market or people about to lose their work focusing, especially, on the efficiency of participatory/active learning methodologies (see figure 1). 


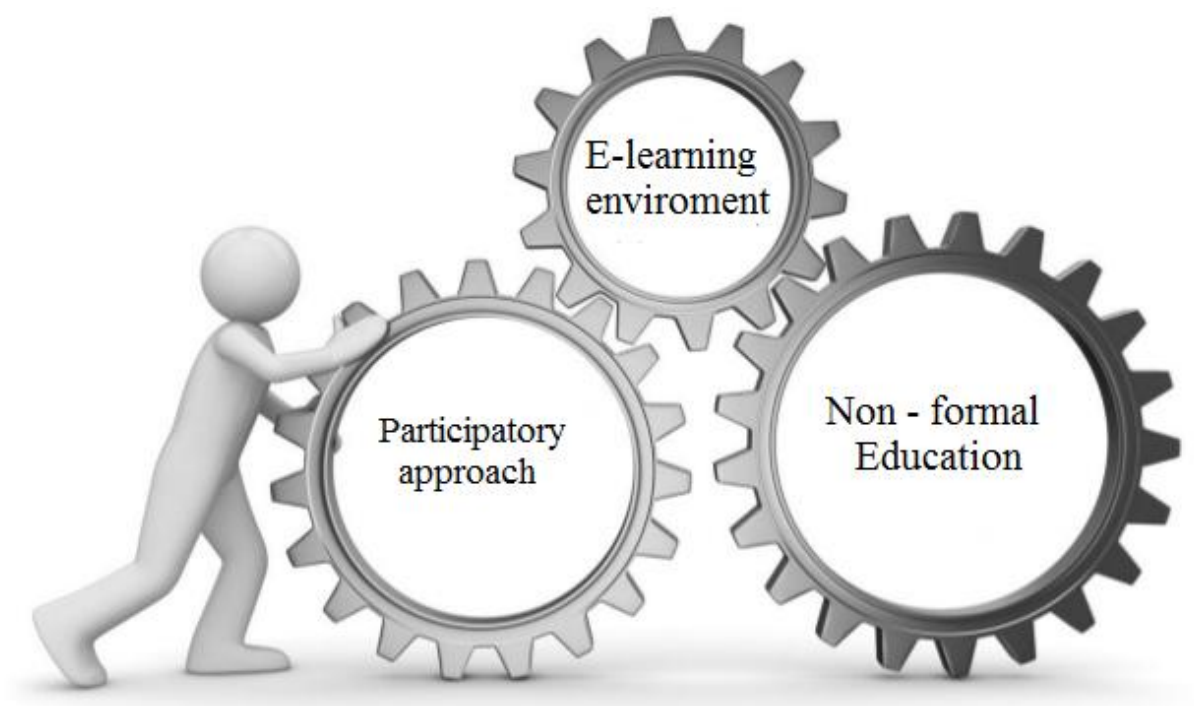

Figure 1 Project methodology

The analysis of adult-elderly learning methodologies will be organized in a public document. It will include basic literature, examples and initiatives of the training centres related to the project issues. It will also gather information, programmes and initiatives related to the project scope, taking into account that one of the objective is the development of a multimedia guide, a sort of a framework containing reference to contents about adult-elderly education as well as best practices and recommendations. Namely:

- The context of participatory/active learning in adult learning environment;

- Methodologies, techniques, etc. that can be applied in adult participatory/active learning; analysis of the claimed benefits; identification of main costs in participatory/active learning;

- Concepts that should be known by institutions, educators, trainers, teachers etc. about adult participatory/active learning - it will be considered the outcomes contained in EU documents, guides, etc., (DGEC, 2012).

- The role of Information and Communication Technology (ICT) in participatory/active learning and their contribution as a tool to facilitate learning;

- Best procedures to measure the benefits and costs in the actual application of participatory education approaches;

- $\quad$ Problems, barriers, etc. in adult participatory/active learning;

- New skills for courses preparation by using a web participatory approach. 
It will be adopted a research methodology which provides the execution of the following preliminary tasks:

- Collecting, data, evidences and information about adult-elderly European projects envisaged to learning methodologies;

- Online survey in the field of adult web participatory learning;

- Gathering of best practice examples in participatory learning.

Since all partners have a wide background in adult education, they will contribute to the creation of the basic data source.

The research will continue with the analysis of collected materials and their classification, e.g. on the basis of different educational and learning actors, learning topics, reference to methodologies or approaches, use or not of new technologies, geographic area, learners age and social status, etc.

Particular attention will be paid to Peer-Assisted Learning Strategies (PALS) which is deemed to be a simple way to engage students in paired reading and discussion of any text. The PALS method will be applied in our training course in order to test how it can be useful in an ICT-based educational program. On this purposes, a chat room will be implemented for emulating the participatory approach. A teacher will assist learners.

The research will provide:

- Comparing data with the literature findings and the survey results;

- Structuring data and data dictionary;

- Pilot experiment detailing;

- Organizing outcomes; conceptual maps, links, cross references, etc.;

- Recommendations list;

- Multimedia guide functional design;

- Usability requirements;

- Mapping the target group interests into the multimedia guide contents.

The research will present the differences encountered in adult-elderly learning methodologies, especially participatory/active learning.

A questionnaire will be prepared and submitted to our target group and semi-structured interviews will be conducted on a selected sample of educational key institutions. The same questionnaire will be used to collect information about the diffusion of web learning technologies. A public document will be produced containing a structured description of best practices in adult-elderly scope.

All the experiences collected will be analyzed and will be chosen the most appropiate and succesful. Will be analyzed the behavior of web learning communities, the digital barriers and the way used in a participatory context to overcome the problems that can affect a participatory learning approach in an 
ICT context. There are considered also the group dynamics that can affect learning groups.

\section{EScAIADE research framework:}

The process adopted to collect information foresees different steps and follows that of the applied research. The differences between basic and applied research have been summarized by Rajasekar, Philominathan and Chinnathambi (Table 1).

Table 1 Differences between basic and applied researches (Rajasekar et al., 2013)

\begin{tabular}{|l|l|}
\hline Basic research & Applied research \\
\hline Seeks generalization & $\begin{array}{l}\text { Studies individual or specific cases without } \\
\text { the objective to generalize }\end{array}$ \\
\hline Aims at basic processes & $\begin{array}{l}\text { Aims at any variable which makes the } \\
\text { desired difference }\end{array}$ \\
\hline Attempts to explain why things happen & Tries to say how things can be changed \\
\hline Tries to get all the facts & $\begin{array}{l}\text { Tries to correct the facts which are } \\
\text { problematic }\end{array}$ \\
\hline $\begin{array}{l}\text { Reports in technical language of } \\
\text { the topic }\end{array}$ & Reports in common language \\
\hline
\end{tabular}

The central aim of our research is to find solutions for the practical problems that arise if you try to apply a participative approach in an e-learning training. This not prevent the attention to theoretical issues. We are persuaded that practical solutions should be grounded on theories and scientific knowledge. Nevertheless, scientific knowledge need observation and data.

Our applied research was also necessary to evaluate the implementation of a participative approach in an ICT-based learning environment. Among issues we also include the cost of the on-line support of trainers and tutors and the difficulties of conciliating the peculiarity of the e-learning approach and the exigency of synchronizing the learning activity between trainees and trainer.

The research has been divided in two sections:

\section{a. Desk research: Adult non-formal learning}

The aim of the desk research is to create the knowledge base necessary to support the project development. In particular, the transformation of traditional training courses in ICT-based participating learning courses.

All partners ought to collect data in order to produce a structured picture of the adult education in their own country, focusing on non-formal learning and 
ICT- based learning. In fact, in the labor world, one assists to the growth of knowledge needed to support the workers' competence. We are persuaded that in the next future non-classroom and non-instructional type of learning will represent a crucial aspect of workers' professionalization. In this perspective, digital applications will contribute to spread the process of knowledge creation, will foster adult learners' collaboration, and will contribute for retaining and improving the productivity of older workers (Gibb \& Fenwick, 2008; Kok, 2015).

Data will be organized in a common structure for an easier comparison:

1. Country legislation [Laws / Regulations]

2. Statistics [Number of adult learners involved, gender and age / Learners' preferences / Costs]

3. Education programs [Sectors / Methodologies / Adult educators recruitment / Learning assessment and recognition]

4. ICT [e-learning, distance learning, and hybrid solutions / barriers towards ICT-based adult learning programs]

5. Notes based on the partner's experience [Best practices / Suggestions/Opinions, etc.]

\section{b. Field research:}

The project foresees that all partners submit a questionnaire and conduct semi-structured interviews in order to better understand the context where the learning experiment will be realized.

The questionnaire has been defined and the following dimensions will be explored:

1. General information [Age / Gender / Marital status / Place of living / Educational degree]

2. Work situation [Occupational status / Employment sector / Employment duration / Task difficulty]

3. ICT skills [Computer usage skills / Computer ownership / Computer use / Social media / Mobile phone usage]

4. Adult education [Education / Training courses participation / Institutions that organized them / Cost of participation / Satisfaction]

5. Need and expectation [Objective of learning / Subject of learning / Methodology / Informal - non-formal education]

6. Barriers [Learning activities barriers / Type of barriers] 


\section{Conclusion}

We described the initial phase of EScAlADE, a transnational project which aims at experimenting the participatory approach in an adult non-formal elearning environment. Although many researchers argued about the importance of both Web 2.0 learning and participating education, at the moment, there are few evidences about how to apply participative models in an ICT environment (Bakia et al., 2012; Mavroudi \& Hadzilacos, 2013).

Our experiment has been defined to be used as a starting point by those who are involved in adult-elderly education.

For this purpose, one of the deliverables of EScAlADE is a multimedia guide: it has been designed as a tool for receiving new materials and new data. It will contain the necessary specification to perform active / participatory courses and will describe how these courses should be organized, how teachers should be trained, how learners should be supported and evaluated. The multimedia guide is conceived as a practical guide which assist staff involved in adult education. At this research stage, its main functional features have been defined, as well as its capabilities, appearance, and interactions with users. It will present an interactive user interface built on the modern usability criteria.

Finally, EScAlADE project rests on the persuasion, agreed by other researchers, that technologies provide many possibilities, but they don't "fix" meanings necessarily (Suthers, 2005). Based on this idea, our research investigates on the practical benefits of a participatory learning approach in an online environment, also tackling the issue of cost tied to the involvement of adults in non-formal learning practices by having digital interactions with others. A cost-benefit tool will be realized for calculating the cost/benefit of a participatory learning approach. It is intended to offer a simple method for evaluating possible improvement options in the design of training courses based on an active / participatory approach.

\section{Acknowledgments}

This paper was supported by the European project EScAlADE "Education Strategies adult education", and reflects the views only of the authors, and the European Commission cannot be held responsible for any use which may be made of the information contained there in.

\section{References}

Bakia, M., Shear, L., Toyama, Y., \& Lasseter, A. (2012). Understanding the Implications of Online Learning for Educational Productivity. Office of Educational Technology, US Department of Education.

Connolly, B. (2008). Adult learning in groups. McGraw-Hill Education (UK). 
DGEC (2012). European Guide Strategies for improving participation in and awareness of adult learning, in Education Policy, 9-16. http://bookshop.europa.eu/en/strategies-forimproving-participation-in-and-awareness-of-adult-learning-pbNC3112514/downloads/ NC-31-12-514-EN-C/NC3112514ENC_002.pdf?FileName=NC3112514ENC_002.pdf $\& S K U=N C 3112514 E N C \_P D F \& C a t a l o g u e N u m b e r=N C-31-12-514-E N-C ; \quad$ last accessed 10.02.2016.

European Commission (EC). (2009). Developing the role of education in a fully-functioning knowledge triangle, Notices from European Union Institutions and Bodies: Official Journal of the European Union. http://eur-lex.europa.eu/legal-content/EN/TXT/?uri= CELEX: 42009X1212 (01); last accessed 10.01.2016.

Eurostat. (2013a). Unemployment rates of the population aged 25-64 by level of education: annual average.

Fejes, A. (2014). Lifelong learning and employability. In Challenging the'European Area of Lifelong Learning' (pp. 99-107). Springer Netherlands.

Gibb, T., \& Fenwick, T. (2008). Older'professionals' learning in an ageist culture: Beneath and between the borders. In Online Proceedings of the Canadian Association for the Study of Adult Education Conference, University of British Columbia, Canada, CASAE.

Gorodetsky, M., \& Barak, J. (2008). The educational-cultural edge: A participative learning environment for co-emergence of personal and institutional growth. Teaching and teacher education, 24 (7), 1907-1918. http://ec.europa.eu/eurostat/tgm/table.do?tab= table $\&$ init $=1 \&$ language $=$ en $\&$ pcode $=$ tps $00066 \&$ plugin $=1$; last accessed 10.01.2016.

Kok, A. (2015). Integration of Web 2.0 Tools in to Non-formal Learning Practices: A Case Study of IBM. Procedia-Social and Behavioral Sciences, 176, 357-370.

Mavroudi, A., \& Hadzilacos, T. (2013). Learning needs analysis of collaborative e-classes in semi-formal settings: The REVIT example. The International Review of Research in Open and Distributed Learning, 14 (5).

McKenzie, P., \& Wurzburg, G. (1997). Lifelong learning and employability. Organisation for Economic Cooperation and Development. The OECD Observer, (209), 13.

Percy, K. (2015). Adult access to learning. Handbook of Educational Ideas and Practices (Routledge Revivals), 296.

Rajasekar, S., Philominathan, P., \& Chinnathambi, V. (2013). Research Methodology. Eprint arXiv: physics/0601009v3, 1-53. http://arxiv.org/pdf/physics/0601009.pdf; last accessed 10.01.2016.

Sharp, C. (2015). Participative transformation learning and development in practising change. Action Learning: Research and Practice, 12 (2), 250-254.

Stephenson, J., \& Yorke, M. (2013). Capability and quality in higher education. Routledge.

Suthers, D. D. (2005). Technology affordances for intersubjective learning: A thematic agenda for CSCL. In Proceedings of th 2005 conference on Computer support for collaborative learning: learning 2005: the next 10 years! (pp. 662-671). International Society of the Learning Sciences. 